\title{
Experimental Study on Static Performance of Deployable Bridge Based on Cable-Strengthened Scissor Structures
}

\author{
Xiaoming Yu $\mathbb{D},{ }^{1,2}$ Yinghua Yang, ${ }^{1}$ Yanxia $\mathrm{Ji}^{3}$ and $\mathrm{Lin} \mathrm{Li}^{2}$ \\ ${ }^{1}$ Department of Civil Engineering, Xi'an University of Architecture and Technology, Xi'an 710055, China \\ ${ }^{2}$ School of Civil Engineering and Architecture, Suqian University, Suqian 223800, China \\ ${ }^{3}$ School of Arts and Sciences, Suqian University, Suqian 223800, China \\ Correspondence should be addressed to Xiaoming Yu; yuxiaoming2020@foxmail.com
}

Received 1 October 2021; Accepted 29 October 2021; Published 17 November 2021

Academic Editor: Wenjie Ge

Copyright ( $) 2021$ Xiaoming Yu et al. This is an open access article distributed under the Creative Commons Attribution License, which permits unrestricted use, distribution, and reproduction in any medium, provided the original work is properly cited.

\begin{abstract}
The deployable bridge based on scissor structures is one of the effective methods to quickly restore traffic after natural and manmade disasters. Scissor structures have the advantages of high storage rate, lightweight, and convenient storage and transportation. However, when scissor structures are used as load-bearing structures, their stiffness and bearing capacity are low. In this study, a three-dimensional deployable bridge based on the cable-strengthened scissor structures was proposed. In addition to rapid expansion, steel cables were used to strengthen scissor structures to improve the stiffness and bearing capacity. Besides, the static loading comparative tests on cable-strengthened scissor structures and traditional scissor structures (cable-free scissor structures) were performed. The results show that the stiffness of the cable-free scissor structure is small, the bending moment of members is large, and the stress distribution is uneven. The stiffness of cable-strengthened scissor structure is significantly improved; the bending moment of members is significantly reduced; and the stress distribution in the member section is more uniform. It is proved that cables can be used to improve the stiffness and load-bearing capacity of scissor structures without affecting the deployability.
\end{abstract}

\section{Introduction and Background}

The deployable bridge system is an ideal solution for rapid traffic recovery after natural and man-made disasters. This bridge should have the characteristics of fast transportation, convenient installation, and rapid dismantling to meet the requirement of rapid erection and multiarea reuse in the assigned areas, and scissor structures can realize this goal. Scissor structures are composed of several scissor units, and each scissor unit is composed of two members connected through the rotary joints (pivots). The units are interconnected through hinges at their end nodes. In this way, scissor structures have a certain degree of freedom, which can be expanded from a compact packaged state to a large deployed state. This kind of structure is an ideal solution for deployable bridges.

Scissor structures have been widely used, and the geometric and kinematic structures have been mainly studied in the past few years. As a subclass of deployable structures, scissor structures have the advantages of high storage rate, easy conversion, and lightweight. Scissor structures are widely used in small structures such as mobile tents and antennas and slightly large structures such as mobile theatres [1], domes [2], and shelters [3]. Since low requirements of the stiffness and bearing capacity are required for scissor structures in most applications, the research mainly focuses on the geometric and kinematic of the structures. Pinero was the first to introduce the concept of the scissor unit [1]. Using simple scissor units, he designed a mobile theatre and won an architectural competition in London in 1961. Following Pinero, Escrig and Valcarcel developed new spatial grids and patterns composed of two- and three-way scissors for deployable arches, domes, and large-scale umbrellas $[4,5]$. Hoberman proposed a novel concept composed of angulated elements that led to the design of radially deploying closed-loop structures [6, 7]. Pellegrino and You 
took Hoberman's concept a step further and discovered generalized angulated elements to be used as a building block [8]. Feray Maden and Kelvin Roovers et al. gave the design methods of planar open-loop scissor structures and space lattice scissor structures, respectively [9, 10]. Decan Mao, Yaozhi Luo, and Zhong You discussed the movability of planar closed-loop scissor structures [11]. Jianguo Cai and Yao Chen et al. studied the motion trajectory and motion singularity of plane closed-loop scissor structures $[12,13]$. Yenal Akgün and Charis J. Gantes proposed a modified scissor-like element (M-SLE), which can change the geometry of the whole system without changing the size of the bars or the span $[14,15]$.

Scissor structures are rarely used as a load-bearing structure of the bridge or building in engineering, and the corresponding mechanical properties are studied insufficiently. Igor Raskin and John Roorda conducted a series of studies on the mechanical performance of scissors columns. First, the compressive and flexural stiffness of linearly arranged scissors columns were derived under the assumption of geometric linearity [16]. Second, the scissors column was equivalent to a segmented column connected by a bar with infinite bending stiffness and a spring between the bars; then the calculation method of the compressive buckling capacity of the segmented column was given [17]. Finally, the geometric nonlinear analysis of the compressive deformation of the scissors column was carried out. Bo Li and San-Min Wang et al. studied the compressive buckling capacity of scissors columns with the consideration of selfweight [18]. Raskin and Roorda compared the stiffness of six scissor structures with different unit geometry [19]. Yu et al. proved theoretically that the steel cables can improve the stiffness and bearing capacity of scissor structures [20]. In recent years, Yuki Chikahiro and Ichiro Ario et al. have been engaged in the research and development of deployable bridges based on scissor structures and conducted a series of theoretical research, numerical simulation, and light vehicle load tests of full-scale bridges. According to the previous research, additional reinforcement members have been proposed to improve the load-bearing capacity of the bridge under static and dynamic loads [21-25].

In this study, a three-dimensional deployable bridge based on a cable-strengthened scissor structure was proposed. Compared to traditional scissor structures (i.e., cablefree scissor structures), the load-bearing capacity and stiffness of the proposed cable-strengthened scissor structure were greatly improved. Previous studies have confirmed that when scissor structures are used as load-bearing structures, the bending moment of members is large, the stress distribution in the member section is uneven, and load-bearing capacity of structures is reduced. In this study, the use of steel cables to the strengthen scissor structure was proposed to improve its bearing capacity and stiffness. Different from reference [20], our scissor unit has only upper and lower steel cables instead of many continuous cables, which can reduce the friction and avoid the complex design of the structure. To study the role of steel cables and pretension in scissor structures, the static loading tests of a cable-free scissor structure and a cable-strengthened scissor structure were performed, and the static performance of the two structures was analyzed and compared through the experimental data. The experimental results show that the stiffness of cable-free scissor structure is small, resulting in a large displacement of the structure, large bending moment of the member, and uneven stress distribution. The stiffness of the cable-strengthened scissor structure is significantly improved; the bending moment of the members is significantly reduced; and the stress distribution is more uniform. As a result, the load-bearing capacity of the cable-strengthened scissor structure is greatly improved.

\section{Description of the Structural System}

Figure 1 shows the schematic diagram of the deployable bridge proposed in this study. The bridge adopts a deck structure; the upper part is a modular deck system; and the cable-strengthened scissor structure is used as the lower bearing structure. The bridge deck system consists of the bridge deck and the lower longitudinal beam. During installation, the end of the longitudinal beam is connected with the buckle at the node of the substructure so as to form the whole deployable bridge system.

The lower bearing structure of the bridge is composed of the cable-strengthened scissor structure based on the modular design. Two steel cables are used to connect the upper and lower nodes of the cable-free scissor unit (Figure 2) to form a planar element (Figure 3). The steel cables in the element do not affect the expansion and contraction of the scissor structure, and the expansion angle can be accurately controlled. When the scissor structure is expanded to the design angle with the help of a deployable controller, the expected expansion shape of the structure is obtained, and the application of pretension is completed simultaneously. The four planar elements can be connected to form a three-dimensional element, that is, a module (Figure 4). Similar to the planar element, the module can expand and contract freely without being affected by the steel cables. When the module is tightened, it can shrink tightly into a bundle, contributing to a high storage rate (Figure 5). To prevent the relative shear deformation between planar elements, two crossed steel cables are added to the upper and lower surfaces of the module to form a geometrically invariant system. The modules are overlapped along the direction of the steel cables to form the bearing structure of the cable-strengthened scissor structure at the lower part of the bridge, as shown in Figure 1.

\section{Test Procedures}

According to the deployable bridge system proposed in this study, a self-made scale model of the lower bearing structure (Figure 5) was used (i.e., cable-strengthened scissor structures) to test its static performance. The relevant conditions of the test are described as follows.

3.1. Introduction of Model-Related Data. The test model: the test model was composed of three three-dimensional elements, and planar elements of the overlapping part were 


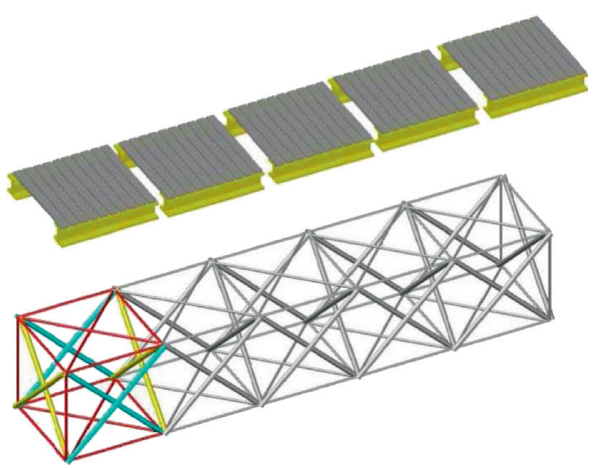

Figure 1: Deployable bridge model.

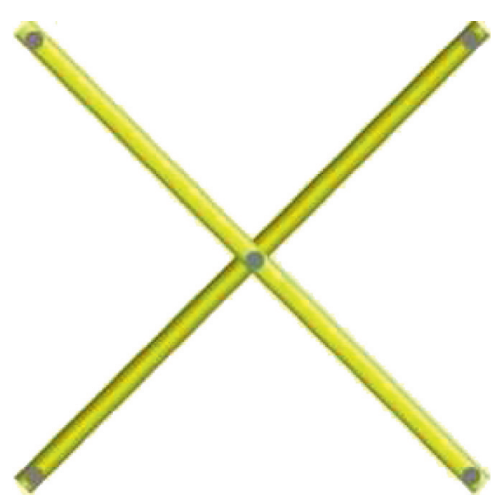

FIgURE 2: Scissor unit.

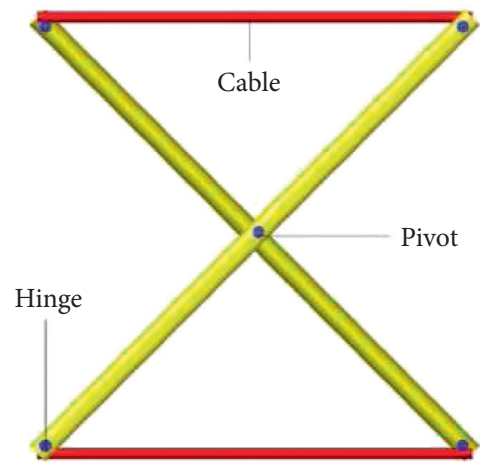

FIgURe 3: Planar element.

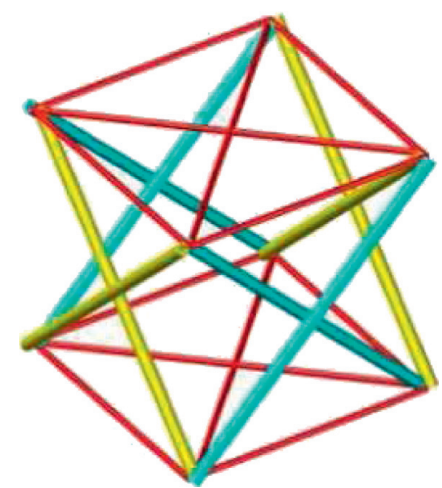

FIGURE 4: Three-dimensional element. removed. The size of each three-dimensional element in three directions after the expansion was $0.5 \mathrm{~m}$. The length, width, and height of the combined test model were $1.5 \mathrm{~m}$, $0.5 \mathrm{~m}$, and $0.5 \mathrm{~m}$, respectively, as shown in Figure 6. The included angle between scissor members in each element was about $45^{\circ}$. In this way, the lengths of all members were equal, and the lengths of all steel cables connecting the scissor structure were equal in the longitudinal, transverse, and vertical directions. In this test, the influence of steel cables and pretension on stiffness and bearing capacity, the axial force, and the bending moment of members were mainly observed. Therefore, a planar structure along the length direction can be tested to achieve the purpose of the test. The opposite structure and scissor units in the width direction only played a supporting role. During the test, the steel cables of the opposite plane structure and the units in the width direction were completely released. As a result, when the tested structure was displaced, restraining effects can be avoided. Since the relative movement of two planar structures in the length direction would not occur, the cross steel cables were not set to prevent relative movement in this test.

3.1.1. Scissor Elements in the Model. The bars of the scissor elements in the model were Q345 B steel commonly used in construction engineering, with the specification of $30 \times 3 \mathrm{~mm}$ steel pipe with an elastic modulus of $2.06 \times 10^{5} \mathrm{MPa}$. The length of each bar was $730 \mathrm{~mm}$; the holes of $10 \mathrm{~mm}$ diameter for connection were set at both ends and the middle of the bar; the distance between the center of the hole diameter at both ends was $707 \mathrm{~mm}$; and the bars were connected by bolts.

The cables in the model consisted of three parts: steel wire rope, cable force measuring device, and wire tightener (Figure 7 ). The $7 \times 19$ steel wire rope with a diameter of $4.2 \mathrm{~mm}$ was used as the steel wire rope, and its elastic modulus was calibrated by an electronic universal testing machine. Finally, the value of its elastic modulus was determined to be $1.88 \times 10^{5} \mathrm{MPa}$. To adjust the tension of the steel cables during the test, tighteners that can adjust the length were added to the steel cables. A section of 304 stainless steel bar with a length of $5 \mathrm{~cm}$ and a diameter of $10 \mathrm{~mm}$ was connected to the steel cable, and its elastic modulus was $1.92 \times 10^{5} \mathrm{MPa}$. Strain gauges were pasted on the surface of the steel bar to control the pretension of the steel cable.

3.2. Introduction to Loading Methods. In this test, the loading of the cable-strengthened and cable-free scissor structure models were conducted to compare the relevant data of the two models.

3.2.1. Loading of the Cable-Strengthened Scissor Structure Model. The four corners of the model were placed on the smooth steel plate, and a $5 \mathrm{~cm}$ thick steel plate was installed at the two points of the upper middle part of the scissor structure along the length direction, and the jack was set in 

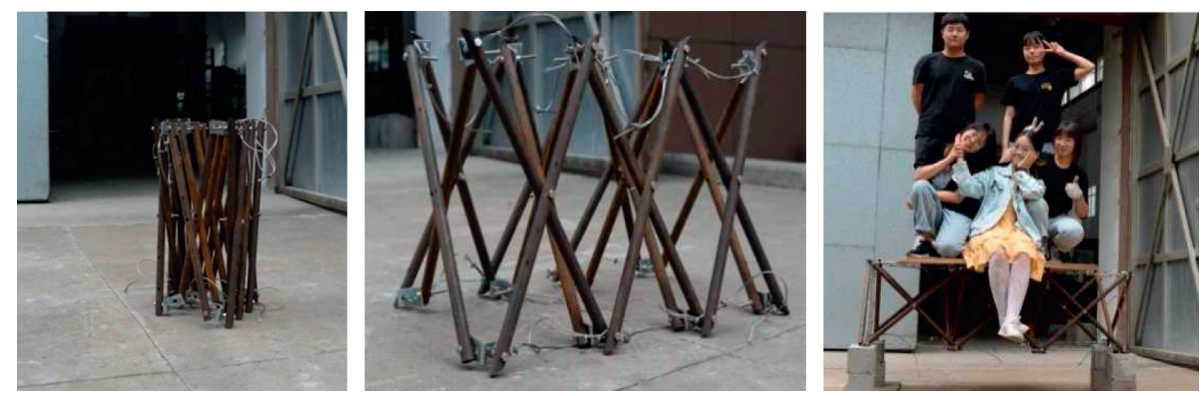

Figure 5: Physical model.

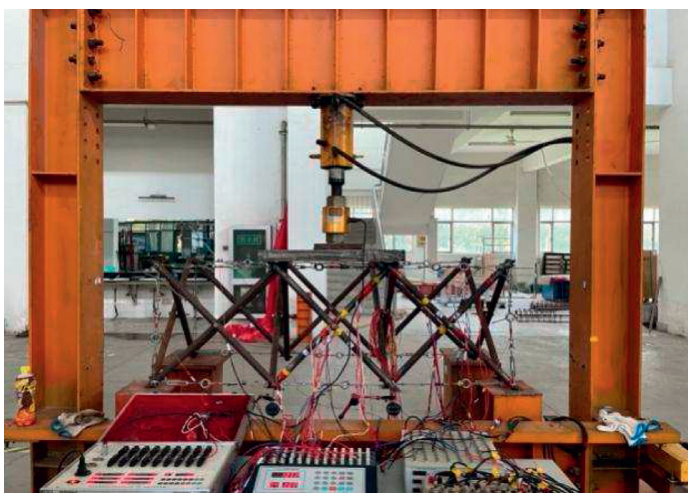

(a)

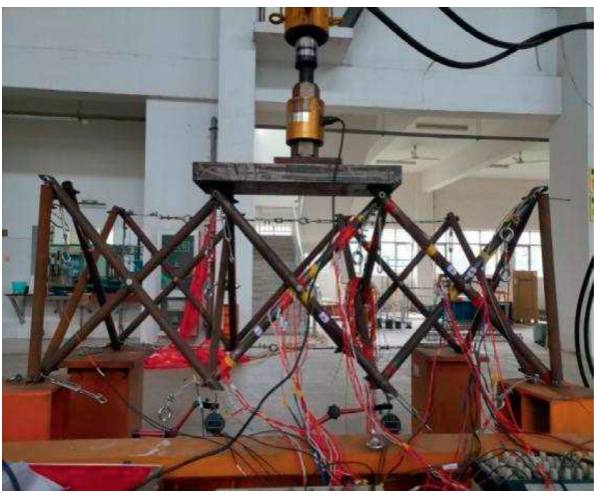

(b)

Figure 6: Test models: (a) cable-strengthened structure and (b) cable-free structure.

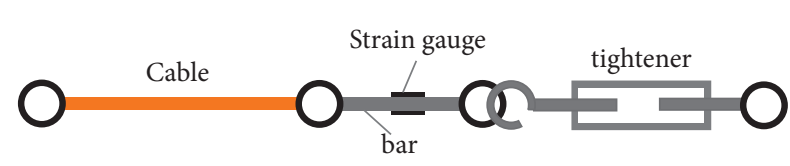

FIgURE 7: Details of steel cable composition.

the middle of the two points for loading, as shown in Figure 6(a). Before the test, the same pretension was applied to all the cables, and the structure was loaded and unloaded repeatedly so as to eliminate the nonlinear effect caused by the cables. In the data measurement, the designed pretension was first applied to the model by adjusting the tightener, and the magnitude of the pretension was obtained by the strain of the cable force measuring device. Second, the strain gauge was zeroed to remove the influence of gravity and pretension on the test data of the model and steel plate. Finally, under each kind of pretension, the structure was loaded step-bystep with no less than five levels, and the data were collected simultaneously.

3.2.2. Loading of Cable-Free Scissor Structure Model. In the model of cable-free scissor structure, all the steel cables were released in the cable-strengthened scissor structure model, and steel pipes were added on both sides of the model; the diameter of the steel pipes was the same as that of the scissor members, as shown in Figure 6(b). The loading conditions were the same as that of the cable-strengthened scissor structure. The structure was loaded three times, and the structure was loaded step by step with at least five levels, and the data were collected simultaneously.

3.3. Data Determination Method. This test aimed to obtain the influence of the steel cable and pretension values on the structural stiffness and bearing capacity, the variation of the axial force, and the bending moment of members with the external load. Because this symmetrical structure bore the symmetrical load, strain gauges were arranged at the designed position in the plane, as shown in Figure 8. Two strain gauges were symmetrically arranged at position $\mathrm{C}$ of bar 1 to measure the surface strain caused by the bending moment (hereinafter referred to as bending strain) on the surface of bar 1 at this point. Two strain gauges were symmetrically arranged at positions A and L of bar 1 to measure the strain caused by the axial force (hereinafter referred to as axial strain) on the surface of bar 1 at these points. Two strain gauges were symmetrically arranged at position $\mathrm{D}$ of bar 2 to measure the bending strain of bar 2 at this point, and two strain gauges were symmetrically arranged at positions $\mathrm{A}$ and $\mathrm{F}$ of bar 2 to measure the axial strain of bar 2 at these points. Two strain gauges were symmetrically arranged at position $\mathrm{D}$ of bar 3 to measure the bending strain of bar 3 here, and two strain gauges were symmetrically arranged at positions B and E of bar 3 to measure the axial strain of bar 3 here. A strain gauge was set on the preset steel bar in each section of the steel cable of the 


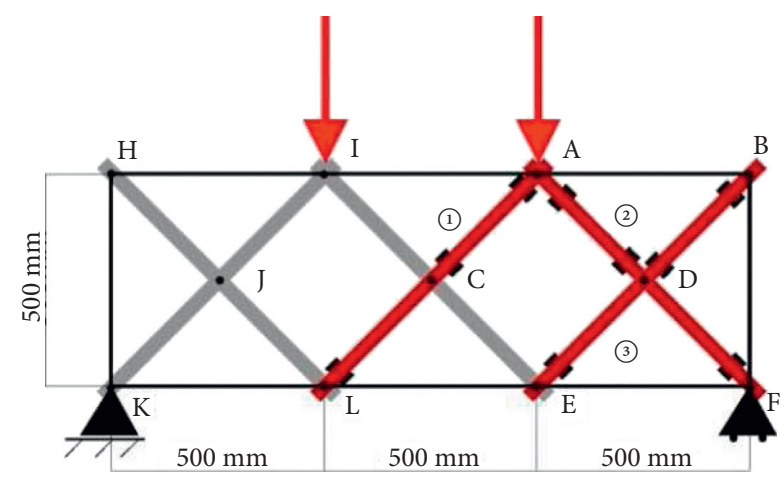

(a)

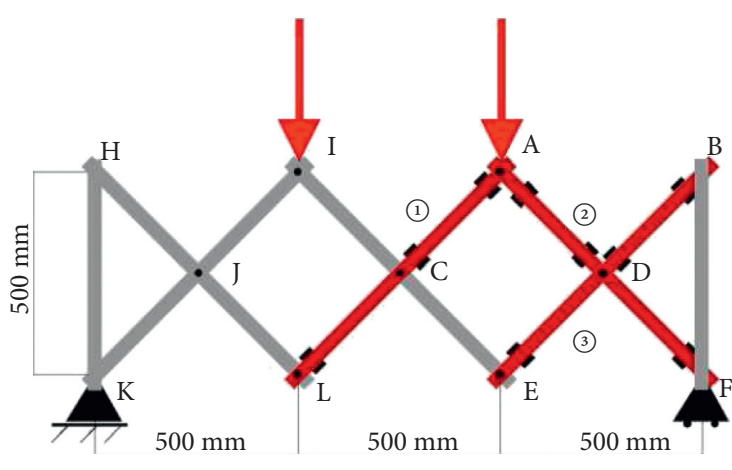

(b)

Figure 8: Layout of measuring points in the test model: (a) cable-strengthened structure model and (b) cable-free structure model.

model to control the pretension applied to the steel cable. Two displacement meters were set at positions $\mathrm{L}$ and $\mathrm{E}$ to measure the vertical displacement of the model during loading.

\section{Analysis of Test Results}

According to the above test scheme, the relationship between node displacement and the load of the two structures are obtained, as well as the relationship between surface strain at measuring points and load. The detailed test results are analyzed as follows.

\subsection{Analysis on Static Performance of the Cable-Strengthened} Scissor Structure. In the static test of the cable-strengthened scissor structure, four different pretensions are applied to the structure. The value of pretension is controlled by the strain gauges of the cable force measuring device. The control value of strain and corresponding tension are listed in Table 1. The influence of pretension on structural stiffness, internal force, and stress distribution is analyzed by using the collected data. The conclusions are obtained as follows: if the steel cables are in service, the pretension value of the steel cables basically has no effect on the stiffness. If the cables are out of service, the stiffness will be significantly reduced. The pretension value rarely affects the internal force of the structure with the change of load, and the stress distribution in the cross section is relatively uniform. The detailed analyses of the test results are as follows.

4.1.1. Effect of Cable Pretension on Stiffness. The load-displacement curves of Nodes L and E are shown in Figure 9. The slope of the load-displacement curve reflects the stiffness of the structure. As shown in Figure 9, each curve can be roughly divided into two obvious sections. The lower part of the curve describes the working state of the upper cables and the lower cables, while the upper part of the curve describes that of the lower cables. First, the slopes of the lower part of the curves are approximately equal. This shows that when the upper and lower cables are all in service, the stiffness of the structure is not affected by the pretension value. Second, the upper part of the curve approximates a straight line with
TABLE 1: Control strain of cable pretension.

\begin{tabular}{lcccc}
\hline Case & Case 1 & Case 2 & Case 3 & Case 4 \\
\hline Strain $(\mu \varepsilon)$ & 300 & 400 & 500 & 600 \\
Pretension $(\mathrm{N})$ & 452 & 603 & 754 & 905 \\
\hline
\end{tabular}

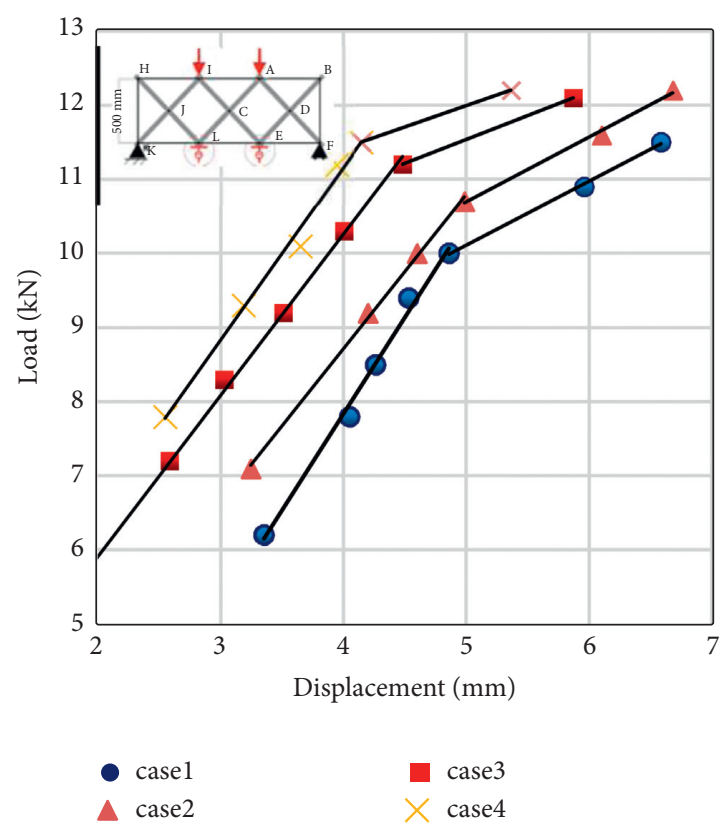

FIGURE 9: Load-displacement curve of the cable-strengthened structure.

a very close slope. This shows that when the upper cables are out of service, the stiffness of the structure is still not affected by the pretension value, but whether the steel cables are in service has a great impact on the stiffness. The turning point of the curve indicates that the upper cables start to quit work at this time.

4.1.2. Effect of Pretension of Steel Cables on Internal Force. To clearly explain the influence of pretension on the internal force of the structure, bar 1 is taken as an example, and its load-bending strain curves and load-axial strain curves 
under different pretensions are obtained, as shown in Figure 10. The longitudinal axis in the figure represents the external load, and the horizontal axis represents the bending strain or axial strain.

4.1.3. Effect of Pretension on Bending Moment. Although the positions of each curve in Figure 10(a) are different, the overall shape of the curve is basically the same as the above load-displacement curve. Each curve can be divided into two distinct sections, corresponding to the working state of the upper cables and the lower cables and that of the single lower cables. The slope of the lower part of the curve is approximately the same. It shows that when the upper and lower cables are all in service, the variation law of the bending moment of the member with the load is hardly affected by the pretension value. The slope of the upper part of the curves is also close, indicating that when the upper cables are out of service, the variation law of the bending moment of the member with the load is still not affected by the pretension value. However, it can be found that the bending moment increases rapidly after the upper cables are out of the service.

4.1.4. Effect of Pretension on the Axial Force. Figure 10(b) shows the influence of pretension on the axial force. These curves show a straight-line rising, and the slope is the same, which shows that the value of pretension has no influence on the change of axial force and has nothing to do with whether the steel cables are in service or not.

4.1.5. Effect of Cable Pretension on Stress Distribution. The value and type of the internal force borne by the member directly determine the design of the cross section. To study the member stress in the cable-strengthened scissor structure, the bending strain at the pivot (position C) and the axial strain of bar 1 are compared. Figure 11 shows ratio curves of bending strain to axial strain of bar 1 with the change of load. The horizontal axis presents the ratio of the bending strain to axial strain, and the longitudinal axis presents the external load. As shown in Figure 11 , the ratio is between 1 and 2 , indicating that the bending strain is greater than the axial strain. In the design of this structure, the effect of bending moment cannot be ignored. The ratio curve of bending strain to axial strain can be divided into two sections, corresponding to the working state of the upper and lower cables and the single working state of the lower cables. In the lower part of the curve, the ratio decreases with the increase of load, which shows that the growth rate of bending moment is less than that of axial force. In the upper part curve, when the upper cables are not in service, the ratio begins to increase rapidly with the increase of load, which also indicates that the bending moment is accelerating. Through the comparison of the curves, it can be concluded that the joint working of the upper and lower cables is important, while this is dependent on specific conditions.
4.2. Static Performance Analysis of the Cable-Free Scissor Structure. After the static test of the cable-strengthened scissor structure, all the steel cables in the structure are released, and vertical bars are added at both ends of the scissor structure; then a stable symmetrical structure is obtained, as shown in Figure 6(b). The same test equipment is used to load the structure three times, and the structure is loaded step by step for no less than five levels. The data of displacement, bending strain, and axial strain of the structure are collected simultaneously. The test results show that the stiffness of the cable-free scissor structure is relatively small, and the overall deformation of the model under load is clear. The bending strain at the pivot of the member is very large, and the bending moment is an important reference index for the design of the cable-free scissor structure.

4.2.1. Stiffness of the Cable-Free Scissor Structure. Figure 12 shows the displacement-load curve of the cablefree scissor structure. Through observation, it can be seen that the displacement-load relationship is linear in general. When the load is large, the relationship between them shows a nonlinear trend. When the load reaches $9 \mathrm{kN}$, the displacement of the structure has exceeded $8 \mathrm{~mm}$, and the overall displacement is extremely large. The above situation is shown in the test: with the increase of load, the middle element moves downward, and the displacement increases gradually. When the load is large, the elements on both sides begin to rotate inward and drive the vertical bars at both ends to rotate inward obviously. The large deformation of the structure makes the structure show a certain nonlinearity. The above data and phenomena show that the stiffness of the cable-free scissor structure is relatively small.

4.2.2. Internal Force of the Cable-Free Scissor Structure. Figure 13 shows the load-bending and load-axial strain curves of bars 1, 2, and 3. In the elastic range, the relationship between load and strain can directly reflect the relationship between load and internal force.

The curves in Figure 13 show obvious linearity. However, when the load is large, individual points deviating from the straight line can be observed. This is caused by the structural geometric nonlinearity due to the large deformation of the structure under the large load. As shown in Figure 13(a), the bending strains of bars 1 and 3 are relatively large. Under the same load, the bending strains of bars 1 and 3 are several times the axial strain in Figure 13(b). It indicates that the bending moment of some members of the cable-free scissor structure is very large, which is unfavorable to the loadbearing capacity of the structure.

\subsubsection{Stress Distribution in the Member Section of the Cable-} Free Scissor Structure. From the above data, it can be seen that bar 2 is located at the support, and the support reaction is large, resulting in a large axial force but a small bending moment. bar 3 is located at the edge of the structure, with small axial force and large bending moment. Therefore, the internal forces of bars 2 and 3 are special. And the 


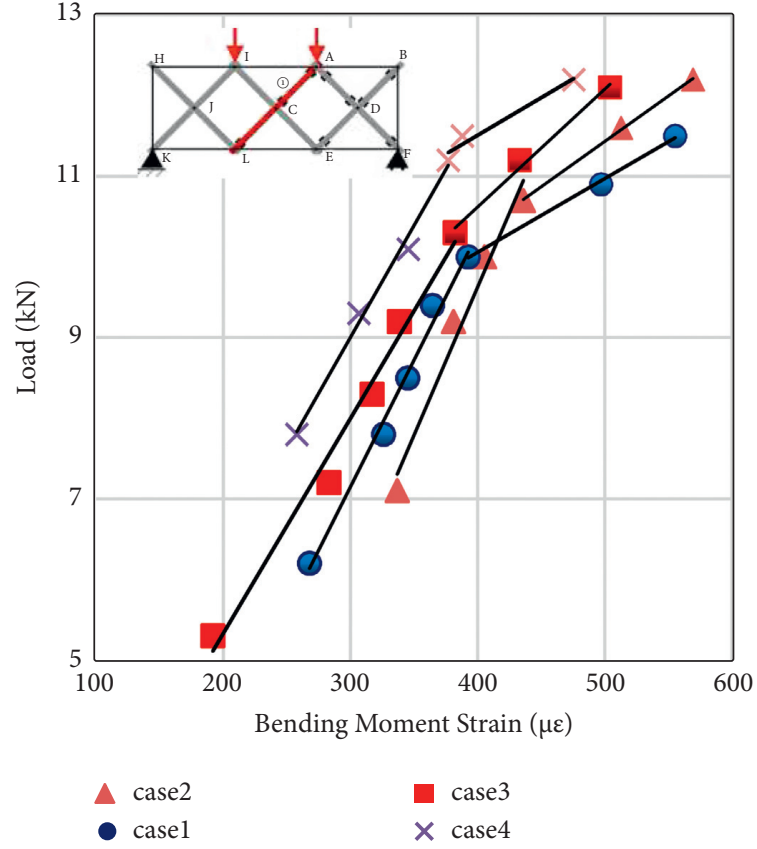

(a)

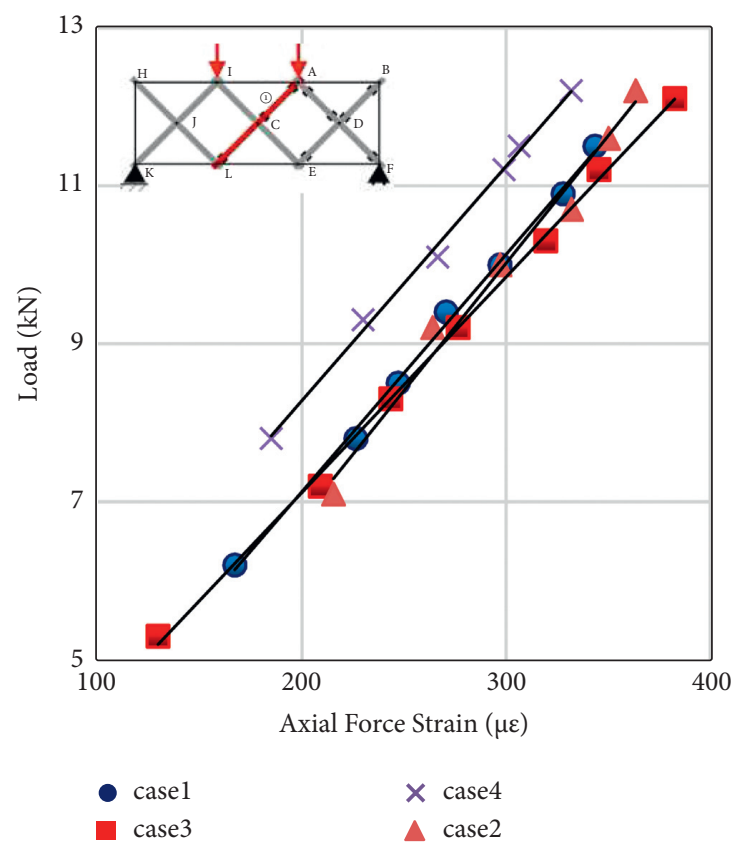

(b)

FiguRE 10: Load-internal force strain curve of bar 1 in the cable-strengthened structure: (a) load-bending strain curves and (b) load-axial strain curves.

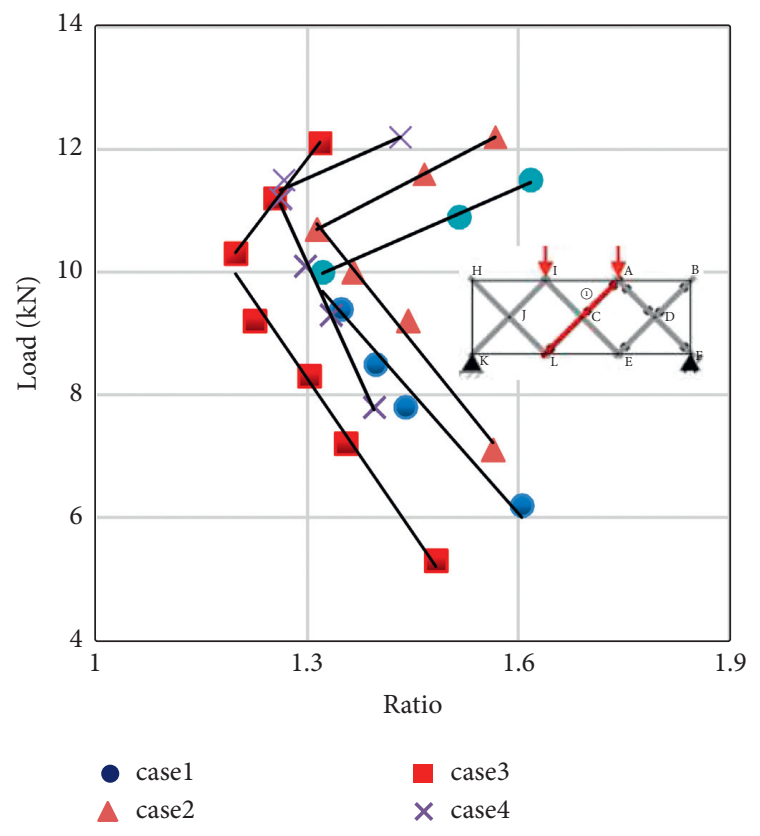

FIGURE 11: Ratio curves of the bending strain and axial strain of bar 1 in cable-strengthened structure.

characteristics of stress distribution in the member section of the cable-free scissor structure are discussed by using bar 1. Table 2 lists the bending strain, axial strain, and their ratio at the pivot of bar 1 under the load. Through the analysis of data, the bending strain under load is much larger than the axial strain. Although the ratio decreases with the increase of load, the bending strain is still several times the axial strain.

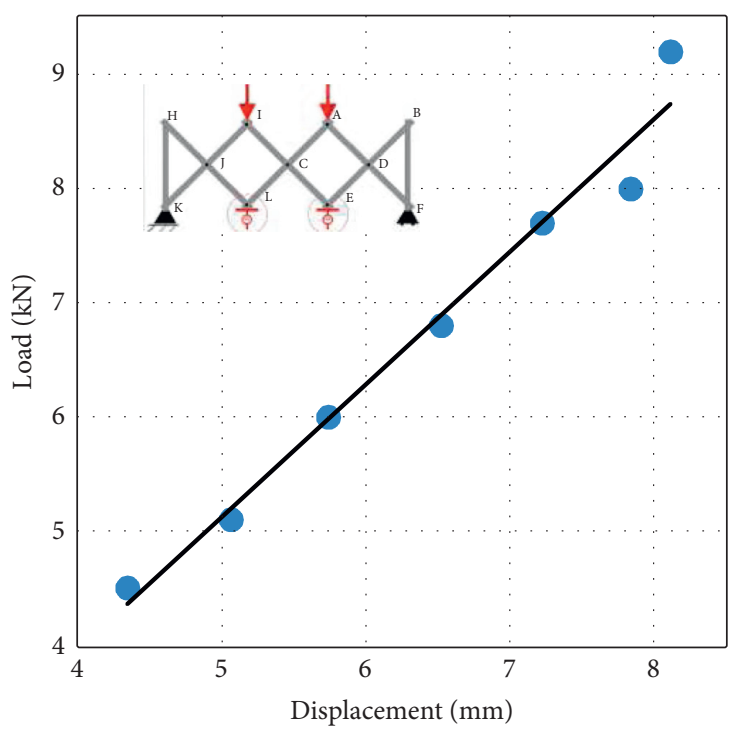

FIGURE 12: Load-displacement curves of the cable-free structure.

As a result, the uneven distribution of stress is caused; the section size of the member is too large; and the strength of the material cannot be fully used, which is not conducive to reducing the weight of the structure.

4.3. Comparison of Static Performance between the Cable-Free Scissor Structure and the Cable-Strengthened Scissor Structure. The data obtained from the two tests are used for the subsequent analysis. When the strain of the cable force measuring device is $300 \mu \varepsilon$, the relevant data of the cable-free 


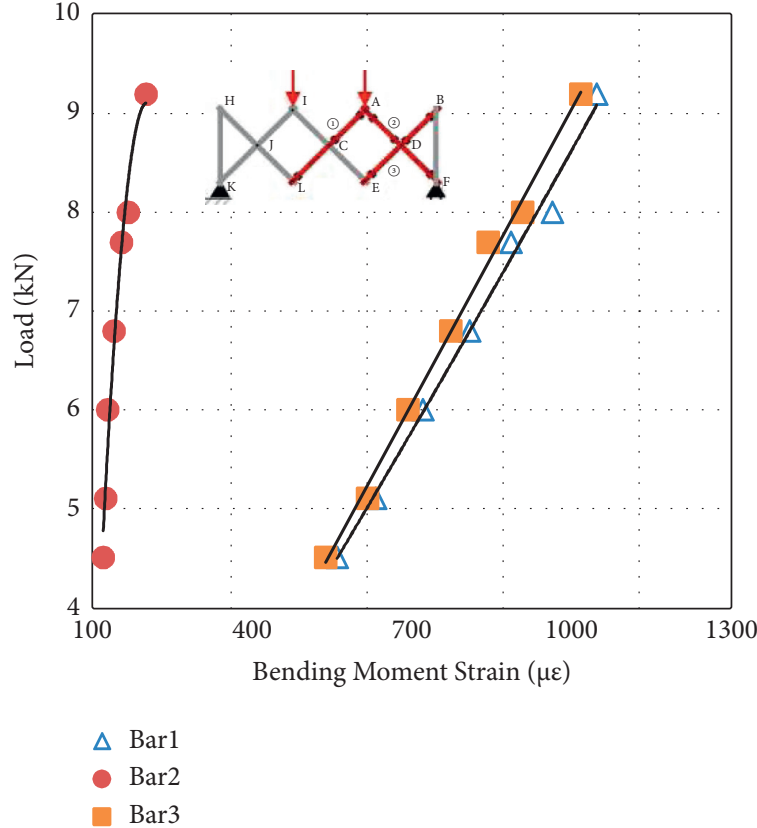

(a)

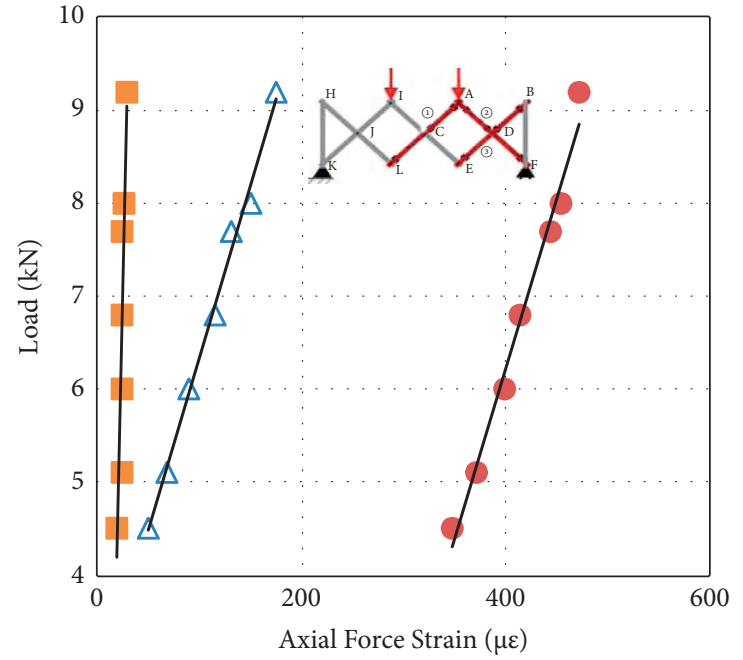

$\triangle$ Barl

- Bar2

- Bar3

(b)

FIGURE 13: Load-strain curve of bar 1 of the cable-strengthened structure: (a) load-bending strain curves and (b) load-axial strain curves.

TABLE 2: Comparison of bending strain and axial strain of bar 1 of the cable-free scissor structure.

\begin{tabular}{lccccccc}
\hline Load $(\mathrm{kN})$ & 4.5 & 5.1 & 6 & 6.8 & 7.7 & 8 & 9.2 \\
\hline Bending strain $(\mu \varepsilon)$ & 635 & 720 & 824 & 927 & 1,019 & 1,109 & 1,208 \\
Axial strain $(\mu \varepsilon)$ & 49 & 67 & 89 & 115 & 131 & 150 & 175 \\
Ratio & 13 & 10.7 & 9.3 & 8.1 & 7.8 & 7.4 \\
\hline
\end{tabular}

and cable-strengthened scissor structures are compared. The analysis results show that the existence of steel cables increases the stiffness of scissor structures, the internal force is relatively reduced, and the stress distribution in the cross section is more uniform. Therefore, steel cables play a very intentional role in the load-bearing of the structure. The specific analysis is as follows.

4.3.1. Comparison of Stiffness. Figure 14 shows the loaddisplacement curves of the cable-free and cable-strengthened scissor structures. Through comparison, it can be found that the slope of the two curves of the cablestrengthened scissor structure is greater than that of the cable-free scissor structure. It indicates that steel cables can significantly improve the stiffness of scissor structures. This conclusion can be proved by comparing displacements under the same load. For example, when the load is $7 \mathrm{kN}$, the displacement of the cable-strengthened scissor structure is about $3 \mathrm{~mm}$, while that of the cable-free scissor structure has reached about $7 \mathrm{~mm}$, and the displacement of the latter is more than twice that of the former.

4.3.2. Comparison of Internal Force. Figure 15 shows the load-bending strain curves of bar 1 of the cable-free and cable-strengthened scissor structures. It is found that the slope of the two straight lines of the cable-strengthened scissor structure is greater than that of the curve of the cablefree scissor structure, which shows that the bending moment of the member of the cable-free scissor structure increases faster with the increasing external load. Under the same load, the strain of the cable-free scissor structure is much larger than that of the cable-strengthened scissor structure, which indicates that steel cables can reduce the bending moment of the members of scissor structures. Figure 16 shows the load-axial strain curves of the two, the slope of the curve is basically the same, and the axial force of the cablestrengthened scissor structure is slightly higher than that of the cable-free scissor structure. To comprehensively compare the stress conditions of the two structures, the sum of bending strain and axial strain is taken for comparison, as shown in Figure 17. It can be seen that the comprehensive strain of the cable-free scissor structure is significantly higher than that of the cable-strengthened scissor structure. The above analysis shows that the application of steel cables can greatly reduce the internal force of scissor structures.

4.3.3. Comparison of Stress Distribution. As shown in Figure 11 and Table 2, the ratio of bending strain to axial strain of the cable-strengthened scissor structure is basically maintained at 1 2 times, while the bending strain of bar 1 in 


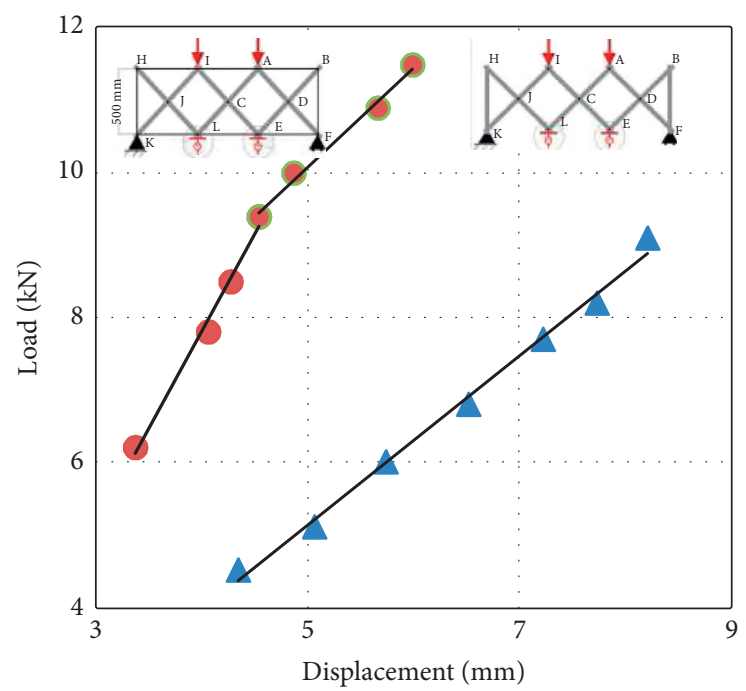

without cables

- with cables

FIGURE 14: Load-displacement comparison curves of structures with and without steel cables.



FIGURE 15: Load-bending strain comparison curves of structures with and without steel cables.

the cable-free scissor structure is several times of the axial strain. It shows that compared with the cable-free scissor structure, the addition of steel cables makes the stress distribution in the member section more uniform, which is conducive to improving the load-bearing capacity of the structure. 


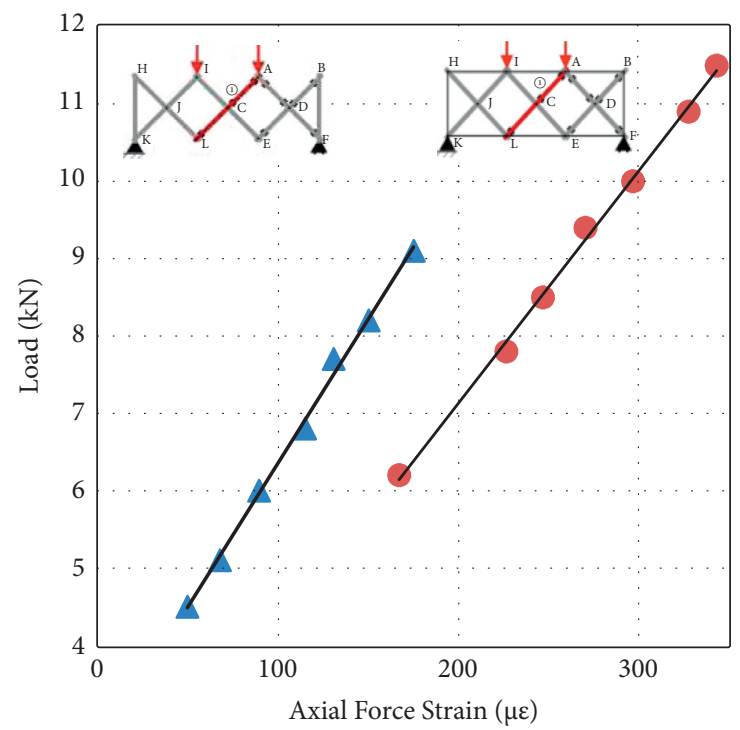

$$
\begin{aligned}
& \text { without cables } \\
& \text { with cables }
\end{aligned}
$$

FIgURE 16: Comparison of the load-axial strain of structures with and without steel cables.

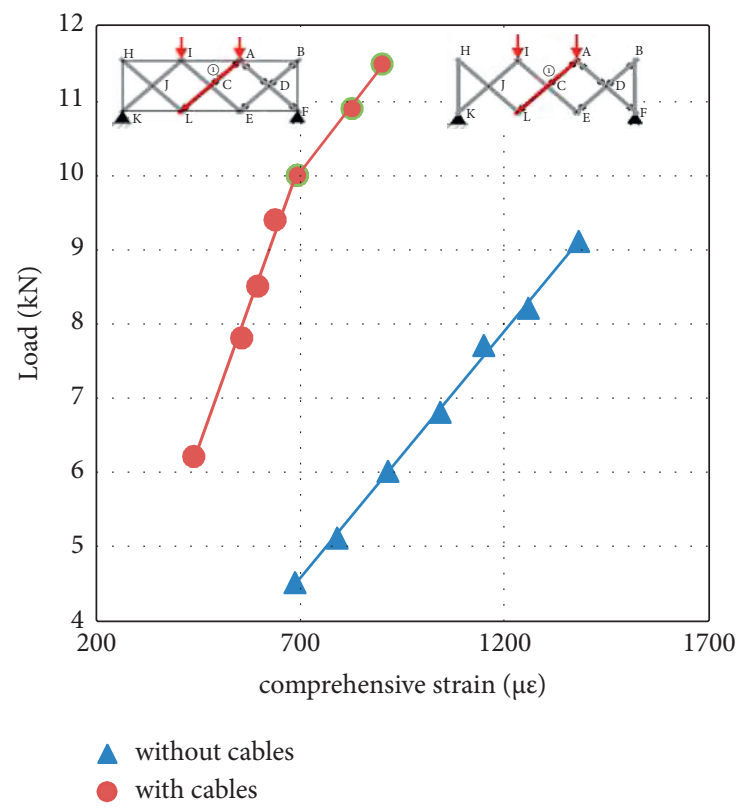

FIGURE 17: Comparison of the comprehensive strain of structures with and without steel cables.

\section{Conclusion}

In this paper, a three-dimensional deployable bridge based on a cable-strengthened scissor structure was proposed. In addition to rapid expansion, steel cables were used to strengthen the scissor structure to improve the stiffness and bearing capacity. The static loading comparative tests on the cable-strengthened and cable-free scissor structures were performed. The conclusions are obtained as follows:

(1) The stiffness of the cable-free scissor structure is relatively small, resulting in a large displacement of the structure, large bending moment of the member section, and uneven stress distribution.

(2) The stiffness of the cable-strengthened scissor structures is significantly improved; the bending moment of the members is significantly reduced; and the stress distribution is more uniform. As a result, the load-bearing capacity of the cable-strengthened scissor structure is greatly improved.

(3) The static loading comparative tests show that the addition of steel cables significantly improves the stiffness of scissor structures, greatly reduces the 
internal force, and the stress distribution in the member section is more uniform so as to improve the load-bearing capacity of scissor structures.

\section{Data Availability}

The data used to support the findings of this study are included within the article.

\section{Conflicts of Interest}

The authors declare that they have no conflicts of interest.

\section{Acknowledgments}

This research was supported by the scientific research support project of "333 High Level Talent Training Project" of Jiangsu Province, China (Grant no. BRA2020241), and Suqian Sci and Tech Program of Jiangsu Province, China (Grant nos. Z2019112, 2021TD04, and K202012), which are gratefully acknowledged.

\section{References}

[1] E. P. Pinero, "Project for a mobile theatre," Architectural Design, vol. 12, pp. 154-155, 1961.

[2] J. B. Valcarcel, F. Escrig, and E. Martin, "Expandable domes with incorporated roofing elements," in Proceedings of the Fourth International Conference on Space Structures, Space Structures, Thomas Telford, London, UK, 1993.

[3] L. A. Mira, A. P. Thrall, and N. D. Temmerman, "Deployable scissor arch for transitional shelters," Automation in Construction, vol. 43, no. 7, pp. 123-131, 2014.

[4] F. Escrig and J. P. Valcarcel, "Geometry of expandable space structures," International Journal of Space Structures, vol. 8, no. 1-2, pp. 71-84, 1993.

[5] F. Escrig, "General survey of deployability in architecture," Mobile and Rapidly Assembled Structures II, vol. 24, pp. 3-22, 1996.

[6] C. Hoberman, "Reversibly expandable doubly-curved truss structure," U.S. Patent and Trademark Office, Washington, DC, USA, U.S. Patent 4,942,700[P], 1990.

[7] C. Hoberman, "Radial expansion/retraction truss structures," U.S. Patent and Trademark Office, Washington, DC, USA, U.S. Patent 5,024,031, 1991.

[8] Z. You and S. Pellegrino, "Foldable bar structures," International Journal of Solids and Structures, vol. 34, no. 15, pp. 1825-1847, 1997.

[9] F. Maden, K. Korkmaz, and Y. Akgün, "A review of planar scissor structural mechanisms: geometric principles and design methods," Architectural Science Review, vol. 54, no. 3, pp. 246-257, 2011.

[10] K. Roovers and N. De Temmerman, "Deployable scissor grids consisting of translational units," International Journal of Solids and Structures, vol. 121, pp. 45-61, 2017.

[11] D. Mao, Y. Luo, and Y. Zhong, "Planar closed loop double chain linkages," Mechanism and Machine Theory, vol. 44, no. 4, pp. 850-859, 2009.

[12] J. Cai, Y. Zhou, Y. Zhu, J. Feng, Y. Xu, and J. Zhang, "Geometry and mechanical behaviour of radially retractable roof structures during the movement process," International Journal of Steel Structures, vol. 16, no. 3, pp. 755-764, 2016.
[13] Y. Chen, L. Fan, and J. Feng, "Kinematic of symmetric deployable scissor-hinge structures with integral mechanism mode," Computers \& Structures, vol. 191, pp. 140-152, 2017.

[14] Y. Akgün, C. J. Gantes, K. E. Kalochairetis, and G. Kiper, “A novel concept of convertible roofs with high transformability consisting of planar scissor-hinge structures," Engineering Structures, vol. 32, no. 9, pp. 2873-2883, 2010.

[15] Y. Akgün, C. J. Gantes, W. Sobek, K. Korkmaz, and K. Kalochairetis, "A novel adaptive spatial scissor-hinge structural mechanism for convertible roofs," Engineering Structures, vol. 33, no. 4, pp. 1365-1376, 2011.

[16] I. Raskin and J. Roorda, "Linear behaviour of a uniform pantographic column in bending and compression," International Journal of Space Structures, vol. 13, no. 4, pp. 187195, 1998.

[17] I. Raskin and J. Roorda, "Buckling force for deployable pantographic columns," WIT Transactions on The Built Environment, vol. 24, 1996.

[18] B. Li, S. M. Wang, C. J. Zhi, X.-X. Xue, and V. Makis, "Analytical and numerical study of the buckling of planar linear array deployable structures based on scissor-like element under its own weight," Mechanical Systems and Signal Processing, vol. 83, pp. 474-488, 2017.

[19] I. Raskin and J. Roorda, "Nonlinear analysis of uniform pantographic columns in compression," Journal of Engineering Mechanics, vol. 125, no. 12, pp. 1344-1348, 1999.

[20] F. Yu, X. Xu, and Y.-z. Luo, "Research on mechanical properties of cable-strengthened scissor-Hinge mechanism," Engineering Mechanics, vol. 38, no. 5, pp. 151-160, 2021.

[21] Y. Chikahiro, I. Ario, and M. Nakazawa, "An experimental study on the design method of a real-sized Mobile Bridge for a moving vehicle," Mobile and Rapidly Assembled Structures IV, vol. 136, pp. 140-152, 2014.

[22] Y. Chikahiro, I. Ario, and M. Nakazawa, "Theory and design study of a full-scale scissors-type bridge," Journal of Bridge Engineering, vol. 21, no. 9, Article ID 04016051, 2016.

[23] Y. Chikahiro, I. Ario, M. Nakazawa et al., "Experimental and numerical study of full-scale scissor type bridge," Automation in Construction, vol. 71, pp. 171-180, 2016.

[24] Y. Chikahiro, I. Ario, P Pawlowski et al., "Dynamics of the scissors-type mobile bridge," Procedia Engineering, vol. 199, pp. 2919-2924, 2017.

[25] K. Chanthamanivong, I. Ario, and Y. Chikahiro, "Smart design of coupling scissors-type bridge," Structures, vol. 30, no. 1, pp. 206-216, 2021. 